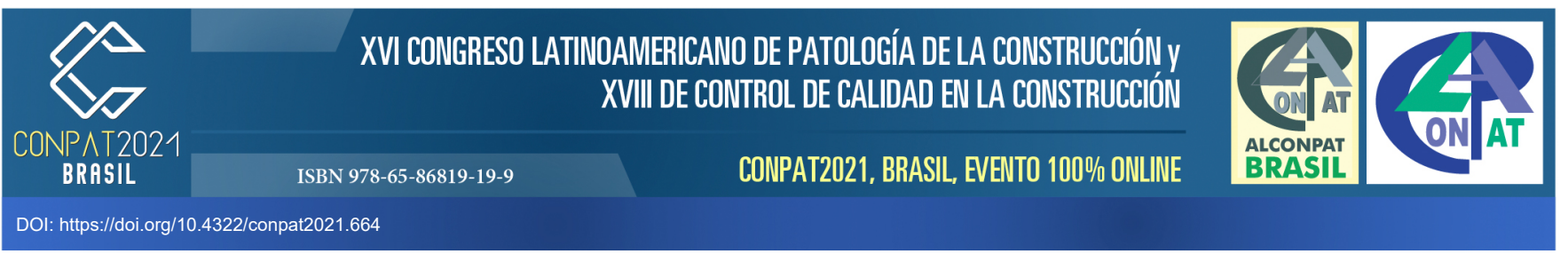

\title{
Manifestações patológicas em vedações verticais inovadoras: origens, causas e técnicas de recuperação.
}

\author{
TS. Barros ${ }^{1 *}$, GM. Da Costa ${ }^{1},{\text { CVSA. De } \operatorname{Vasconcelos}^{1} \text {, EL. Da Silva Júnior }}^{1}$, JM. De Oliveira ${ }^{1}$, \\ JFB. Baía ${ }^{1}$, AC. Lordsleem Júnior ${ }^{1}$ \\ *teosousa94@gmail.com \\ ${ }^{1}$ Pós-Graduação em Engenharia Civil, Escola Politécnica, Universidade de Pernambuco, Recife, Brasil
}

\section{RESUMO}

As vedações verticais inovadoras, surgem como alternativa a alvenaria tradicional, devido a busca por produtividade. O objetivo consiste em apresentar as principais causas de suas manifestações patológicas. A metodologia baseia-se na revisão bibliográfica, o critério para classificação está fundamentado no Sistema Nacional de Avaliações Técnicas (SINAT). Desta forma, escolheramse cinco tecnologias de vedações verticais sem função estrutural que possuíssem maior diversidade entre os materiais constituintes de sua composição. Os resultados da pesquisa demonstraram que dentre as manifestações patológicas incidentes, as mais recorrentes são fissuras e problemas de umidade, resultantes de deficiência no projeto e no processo de construção. As principais contribuições deste trabalho consistem em agrupar o conhecimento das manifestações patológicas mais frequentes em vedações verticais inovadoras, descrevendo as principais causas.

Palavras-chave: Vedações verticais inovadoras; manifestações patológicas; causas.

\begin{abstract}
The innovative vertical seals appear as an alternative to traditional masonry, due to the search for productivity. The purpose of the present work is to present the main causes of the problems from the studied sealings. The methodology is based on the bibliographic review, the classification criterion is based on the National System of Technical Assessments (SINAT). In this way, five vertical sealing systems without structural function were chosen, which had greater diversity among the constituent materials of its composition. The results of the research showed that among the incident problems, the most recurrent are cracks and moisture problems, resulting from deficiency in the design and construction process. The main contributions of this work are to group the knowledge of the most frequent pathological manifestations in innovative vertical sealings, describing the main causes.
\end{abstract}

Keywords: Innovative vertical sealings; pathological manifestations; causes. 


\section{INTRODUÇÃO}

A indústria da construção civil está constantemente se aprimorando conforme o avanço tecnológico e lançando inovações no mercado. De acordo com a Organização para Cooperação Econômica e Desenvolvimento (OCDE), uma inovação corresponde à implementação de um produto novo ou de um mesmo produto com melhorias significativas, seja este um bem ou serviço (OCDE, 2005). Segundo a Câmara Brasileira da Indústria da Construção (CBIC, 2016) as inovações no âmbito da construção civil podem ser classificadas de diversas maneiras, sendo uma delas definida pelos seguintes termos de inovações: institucional, organizacional, comercial e tecnológica. Ainda, a CBIC afirma que as inovações tecnológicas estariam relacionadas à utilização de novos componentes, produtos, sistemas, procedimentos e equipamentos.

Por sua vez, a NBR 15.575:2013 define uma inovação tecnológica como um aperfeiçoamento tecnológico, proveniente de atividades de pesquisa, aplicado ao processo de produção do edifício, tendo como objetivo a melhoria de desempenho, qualidade e custo do edifício ou de um sistema. No que tange às tecnologias construtivas de uma edificação, pode-se citar como exemplo de inovação tecnológica as tecnologias de vedações verticais.

São pouco utilizadas nas edificações, como salienta Sobrinho (2018) ao destacar o caso da alvenaria de bloco de gesso que ainda é dificilmente empregada pelas construtoras no Brasil. Desta forma, por serem pouco aplicadas e/ou passarem a ser utilizadas recentemente na construção civil, quando comparado à alvenaria tradicional, as tecnologias construtivas inovadoras de vedações apresentam a necessidade de um maior aprofundamento de estudos científicos no âmbito das manifestações patológicas e técnicas de recuperação.

Neste sentido, o objetivo dessa pesquisa é fazer um levantamento, a partir da análise bibliográfica, das principais manifestações patológicas que são encontradas em algumas tecnologias de vedação vertical inovadoras. Desta maneira, busca-se apresentar aspectos como origens, causas, técnicas de terapia e medidas de prevenção visando elencar as medidas/cuidados que se deve ter ao utilizar as inovações tecnológicas das vedações verticais. Ainda, é apresentado um plano de manutenção preventiva que engloba todas as tecnologias estudadas, a fim de garantir a manutenção do desempenho da edificação ao longo do tempo.

\section{METODOLOGIA}

O presente trabalho é caracterizado como exploratório visto que busca uma melhor descrição sobre os objetos do estudo. A pesquisa foi dividida em duas etapas, sendo a primeira a seleção das vedações verticais inovadoras e na segunda a aplicação da metodologia Preferred Reporting Items for Systematic Reviews and Meta-Analyses - PRISMA. Desta forma, no que tange à escolha das vedações inovadoras, tomou-se como referência as diretrizes do Sistema Nacional de Avaliação Técnica de Sistemas Inovadores e Convencionais (SINAT), onde informa que uma tecnologia construtiva inovadora consiste em sistema ou subsistema construtivo que não seja objeto de norma brasileira prescritiva e não tenha tradição de uso no território nacional. Estes processos constituem inovações em relação ao processo convencional da construção civil no Brasil. Assim sendo, foram selecionadas as cinco tecnologias de vedações verticais sem função estrutural previstos pelo SINAT:

- Painéis pré-fabricados de chapas delgadas vinculadas por núcleo de isolante térmico rígido;

- Fachadas leves em Steel Frame;

- Vedações verticais interna de bloco de gesso;

- Sistema de vedações verticais internas e externas sem função estrutural de painéis vazados de geopolímero;

- Painel de vedação sem função estrutural pré-fabricado em concreto.

Após esta fase, aplicou-se os procedimentos do PRISMA para a seleção e sintetização da literatura existente. Os artigos potencialmente úteis selecionados para esse estudo foram encontrados no 
Portal de Periódicos da Coordenação de Aperfeiçoamento de Pessoal de Nível Superior (CAPES) e no Google Acadêmico.

A busca no Portal de Periódicos da Capes foi realizada no campo "por assunto" e as palavraschaves em inglês empregadas foram:

- Em inglês: "innovative vertical sealing", "pathological manifestations", "performance", "hollow geopolymer panels", "problems", "wall masonry", "external wall", "block", "brick", "plaster" e "Light Steel Frame";

- Correspondência ao português: "vedações verticais inovadoras", "manifestações patológicas", “desempenho", "painéis vazados de geopolímero”, "problemas”, "alvenaria de parede", "bloco", "tijolo", "gesso" e "estrutura de aço leve".

Tais palavras foram combinadas entre si para cada tecnologia pesquisada. Adicionalmente, utilizou-se os operadores booleanos "END" e "OR", com o objetivo de delimitar os resultados das buscas. Na fase de seleção, foram incluídos os artigos revisados por pares, com até treze anos de publicação (de 2007 a 2020) e publicados nos idiomas português e inglês. Posteriormente, foram excluídos os artigos que não continham tópicos de interesse aos temas da pesquisa, por meio da leitura dos títulos e dos resumos. Acrescenta-se que foram incluídos no estudo alguns trabalhos (artigos, dissertações e teses) oriundos de busca por outras fontes como o Google Acadêmico e portais de instituições de ensino superior. A Figura 1 apresenta o fluxograma da seleção dos artigos. $\begin{array}{lll}\text { Identificação } & \text { Triagem } & \text { Elegibilidade }\end{array}$

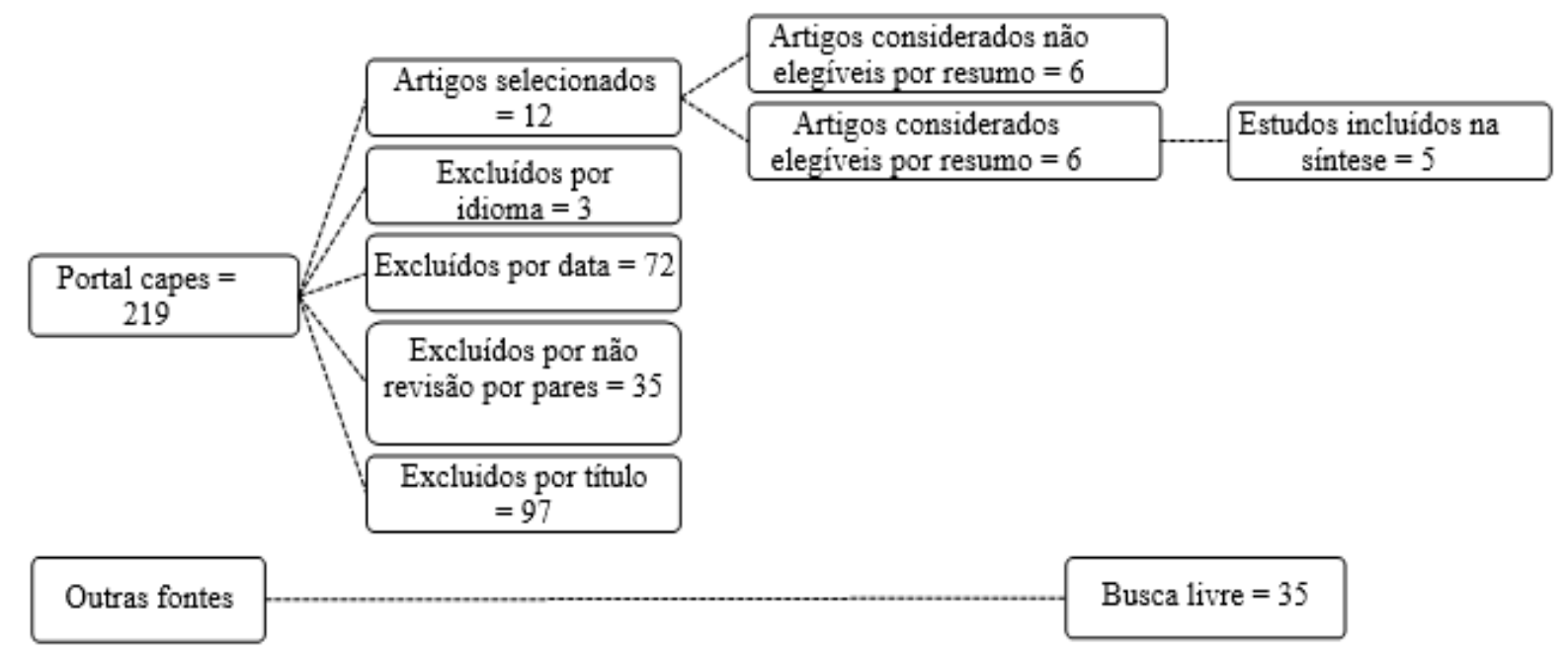

Figura 1 - Fluxograma da seleção dos artigos.

Fonte: Autores (2020)

\section{PATOLOGIA DAS VEDAÇÕES VERTICAIS INOVADORAS}

No âmbito da engenharia civil, patologia corresponde à ciência responsável por estudar as causas, mecanismos de ocorrência e consequências dos erros nas construções (LIMA, 2015). Segundo Lira (2019), as manifestações patológicas ocorrem quando uma edificação apresenta algum problema em sua integridade, comprometendo o desempenho do edifício ou de suas partes, por meio de sinais externos, também denominados de sintomas.

As vedações verticais, assim como qualquer outro sistema de uma edificação, estão sujeitas à perda de desempenho devido ao surgimento de manifestações patológicas. Em decorrência disso, o comprometendo de suas funções é eminente. Segundo a NBR 15575, os problemas supracitados decorrem, sobretudo, de falhas no projeto, na fabricação, na instalação, na execução, na montagem, no uso ou na manutenção dos produtos ou sistemas da edificação (ABNT, 2013). Nas seções seguintes, será apresentado uma abordagem sistemática sobre os principais problemas 
identificados por alguns pesquisadores, no que se refere às tecnologias selecionadas para o presente estudo.

\subsection{Painéis pré-fabricados de chapas delgadas vinculadas por núcleo de isolante térmico rígido.}

A tecnologia construtiva formada por painéis pré-fabricados de chapas delgadas vinculadas por núcleo de isolante térmico rígido podem ser constituídas por chapas delgadas de aço pré-pintadas (SINAT N-10, p.4, 2014).

No que tange ao núcleo dos painéis, a Diretriz SINAT N-010 informa que podem ser de poliestireno expandido (EPS), poliestireno extrudado (XPS), poliuretano (PUR) e poli- isocianurato (poliuretano modificado - PIR).

Segundo Lima (2016), existem no mercado chapas com ou sem perfis estruturais de aço (guias e montantes), que podem ser incorporados ao painel na fase de fabricação ou serem montados no local definitivo juntamente com a montagem dos painéis. De acordo com a Diretriz SINAT N-10, não é recomendável o uso da tecnologia reforçada com perfis de aço em ambientes de atmosferas industriais e marinhas, tendo em vista o alto grau de agressividade associado (classe de agressividade III e IV, da NBR 6118/2014), Figura 2. As manifestações patológicas mais comuns estão relacionadas com a estrutura metálica dos painéis. Desse modo, no tocante aos problemas mais recorrentes em estruturas de aço, Pravia e Betinelli (2016) classificam em seis tipos principais, conforme elencados no Quadro 1.

Quadro 1 - Síntese das principais manifestações patológicas no aço

\begin{tabular}{|l|l|l|}
\hline $\begin{array}{l}\text { Manifestaçõe } \\
\text { Patológicas }\end{array}$ & Origem & \multicolumn{1}{c|}{ Principais Causas } \\
\hline $\begin{array}{l}\text { Corrosão } \\
\text { localizada }\end{array}$ & $\begin{array}{l}\text { Projeto e/ou } \\
\text { execução }\end{array}$ & $\begin{array}{l}\text { Causada por deficiência de drenagem das águas pluviais e } \\
\text { deficiências de detalhes construtivos, permitindo o acúmulo } \\
\text { de umidade e de agentes agressivos. }\end{array}$ \\
\hline $\begin{array}{l}\text { Corrosão } \\
\text { generalizada }\end{array}$ & $\begin{array}{l}\text { Projeto e/ou } \\
\text { execução }\end{array}$ & $\begin{array}{l}\text { Causada pela ausência de proteção contra o processo de } \\
\text { corrosão. }\end{array}$ \\
\hline $\begin{array}{l}\text { Deformações } \\
\text { excessivas }\end{array}$ & $\begin{array}{l}\text { Projeto e/ou } \\
\text { execução }\end{array}$ & $\begin{array}{l}\text { Causadas por sobrecargas ou efeitos térmicos não previstos, } \\
\text { ou ainda, deficiências na disposição de travejamentos. }\end{array}$ \\
\hline $\begin{array}{l}\text { Flambagem } \\
\text { local ou global }\end{array}$ & $\begin{array}{l}\text { Projeto e/ou } \\
\text { execução }\end{array}$ & $\begin{array}{l}\text { Causadas pelo uso de modelos estruturais incorretos para } \\
\text { verificação da estabilidade, ou deficiências no enrijecimento } \\
\text { local de chapas, ou efeitos de imperfeições geométricas não } \\
\text { consideradas no projeto e cálculo. }\end{array}$ \\
\hline $\begin{array}{l}\text { Fratura e } \\
\text { propagação de } \\
\text { fraturas }\end{array}$ & $\begin{array}{l}\text { Projeto e/ou } \\
\text { execução }\end{array}$ & $\begin{array}{l}\text { Falhas estas iniciadas por concentração de tensões, devido a } \\
\text { detalhes de projeto inadequados, defeitos de solda, ou } \\
\text { variações de tensão não previstas no projeto. }\end{array}$ \\
\hline
\end{tabular}

Fonte: Pravia e Betinelli (2016)

De acordo com Souza e Sacchi (2017) as manifestações patológicas presentes nas estruturas metálicas originam-se nas mais diversas fases do empreendimento, desde a fase de projeto até a fase executiva como deficiência em detalhes construtivos ou até mesmo adquiridas, gerando o processo da corrosão.

Pode-se observar no Quadro 1 que a corrosão (Figura 3) está entre as principais manifestações patológicas que ocorrem em estruturas de aço, além de deformações relacionadas à flambagem e a fraturas excessivas. 


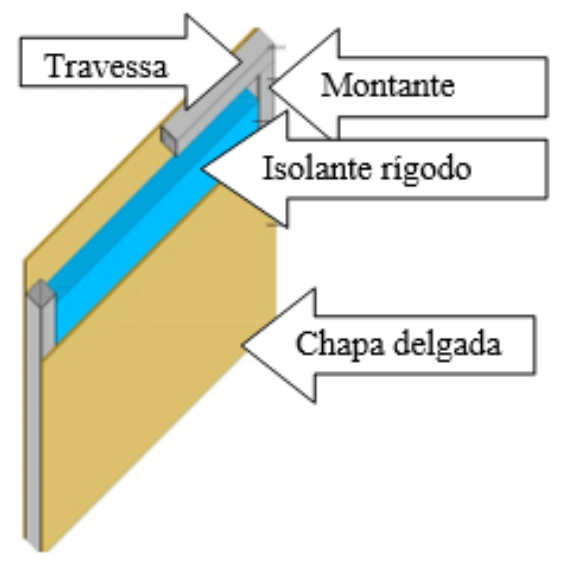

Fonte: Diretriz SINAT N-10 (2020)

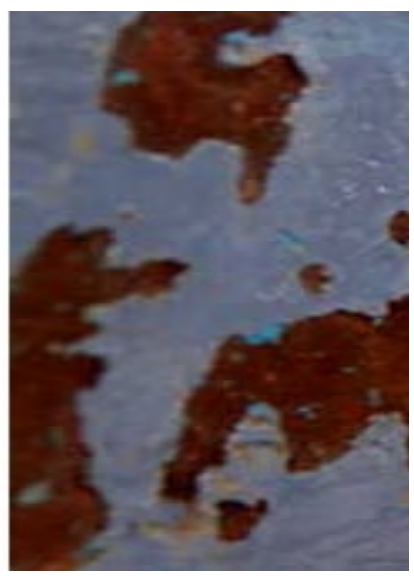

Figura 3 - Corrosão em Painel de chapas delgadas de aço Fonte: IBDA (2020)

Segundo Pannoni, (2007), recomenda que os elementos que apresentarem sinais de corrosão ou que venham a receber algum tratamento em suas superfícies devem passar previamente por uma lavagem com água e tensoativos neutros, esfregando-se com uma escova de nylon. Após a lavagem, seca-se a superfície naturalmente ou com ar comprimido limpo e seco (SIS 0559 00, 1967). Pannoni (2007) cita a pintura como principal meio de proteção dos elementos metálicos. Para isso, são utilizados pigmentos constituídos por partículas sólidas finamente divididas e insolúveis ao meio, com a finalidade de conferir, sobretudo, cor, opacidade, certas características de resistência e outros efeitos. Segundo o mesmo autor, tais pigmentos são divididos em dois grupos, ativos e inertes, os quais conferem respectivamente, cor e proteção aos metais. Os pigmentos anticorrosivos mais utilizados nas tintas de proteção ao aço são: zarcão, fosfato de zinco, zinco metálico, cromato de zinco, óxido de ferro e alumínio. A diretriz SINAT - DAtec $\mathrm{N}^{\circ} 038$, que apresenta as diretrizes para execução das Casas Fisher que utilizam de painéis de chapas delgadas com núcleo isolante térmico rígido, recomenda um período mínimo de 8 anos para a substituição ou avaliação criteriosa do estado das pinturas existentes nas casas.

\subsection{Fachadas leves em Steel Frame.}

O Light Steel Framing (LSF) é uma tecnologia construtiva industrializada, de concepção racional, que permite uma construção a seco, padronizada e muito utilizado nos EUA (ANDRADE, 2017). Segundo Crasto (2005), no final da década de 90 algumas construtoras brasileiras começaram a importar kits em LSF para construção de residências unifamiliares, desde então essa tecnologia tem passado por um processo de melhoria na sua cadeia produtiva.

Segundo Handa (2019), no que tange às recomendações técnicas nacionais, além das diretrizes No003 e No009 publicadas pelo SINAT, tramita uma comissão de estudo de sistemas construtivos LSF (Comissão de Estudo ABNT/CE 002: 125.004), que objetiva estabelecer critérios de desempenho, projeto e execução, a qual passa por revisões semanais e resultará na norma intitulada "Light Steel Framing - Sistemas construtivos estruturados em perfis leves de aço conformados a frio, com fechamento em chapas delgadas".Trata-se de uma tecnologia constituída por perfis metálicos leves com fechamento executado em painéis de gesso acartonado, placas cimentícias ou tiras de madeira. Devido seu ótimo desempenho térmico, seu uso pode contribuir significativamente para redução do consumo de energia em locais de clima frio (LOHMANN e SANTOS, 2020). 
Apesar dos preconceitos enfrentados no Brasil, o LSF tem se mostrado uma tecnologia rápida, durável e flexível, atendendo às condições exigidas para construções residenciais e comerciais, sendo, portanto, uma alternativa viável frente a outros sistemas tradicionais (HANDA, 2019).

Em se tratando dos problemas patológicos, escopo principal desse trabalho, salienta-se que a literatura existente é escassa. Apesar disso, é possível constatar que os problemas mais recorrentes são oriundos, majoritariamente, por falhas de projeto e execução. A Figura 4 permite visualizar claramente o contorno das placas de uma fachada em LSF, tal problema é decorrente de juntas com tratamentos defeituosos (HOFMANN, 2015).

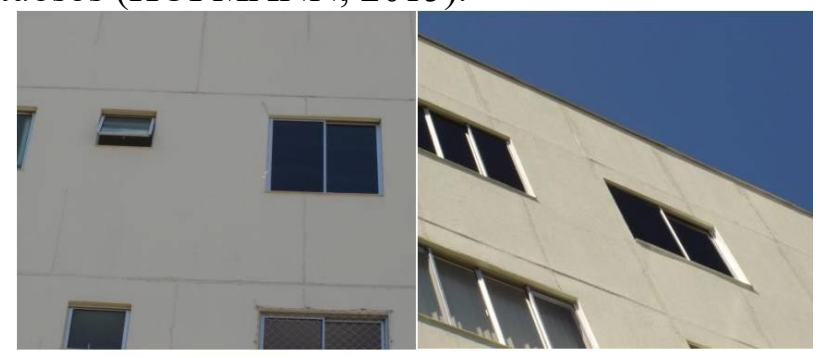

Figura 4 - Contorno de placas em fachadas LSF

Tais problemas são ainda mais recorrentes em edificações de interesse social. Andrade (2017) menciona uma grande reincidência dos problemas identificados no conjunto habitacional objeto de seu estudo, apontando para possíveis falhas na concepção do projeto, uma vez que o autor verifica indícios de que a construtora em questão seguiu as satisfatoriamente as recomendações técnicas. Ainda segundo Andrade (2017), muitos problemas nesse tipo de edificação são decorrentes de ampliações sem a devida compatibilização entre os diferentes sistemas construtivos, resultando no aparecimento de fissuras e trincas devido às diferentes movimentações nos encontros entre os sistemas de vedação.

O Quadro 2 apresenta os principais problemas mencionados na literatura existente, elencando-os com suas respectivas origens e consequências.

Quadro 2 - Síntese das principais manifestações patológicas identificadas por pesquisas envolvendo o estudo de LSF

\begin{tabular}{|c|c|c|c|}
\hline Autores & Manifestações Patológicas & Origem & Causas \\
\hline $\begin{array}{l}\text { Handa } \\
(2019) ; \\
\text { Campos e } \\
\text { Souza } \\
(2010)\end{array}$ & $\begin{array}{l}\text { Problemas com } \\
\text { estanqueidade nas interfaces, } \\
\text { permitindo a ocorrência de } \\
\text { infiltrações e conduzindo à } \\
\text { formação de fissuras }\end{array}$ & $\begin{array}{l}\text { Projeto ou } \\
\text { Execução }\end{array}$ & $\begin{array}{l}\text { Falta de utilização de fita adesiva (flashing) ou } \\
\text { cantoneira metálica nos vértices das aberturas das } \\
\text { janelas; Cortes indevidos nos painéis para passagem de } \\
\text { instalações; Falhas quanto a instalação de telas no } \\
\text { tratamento de juntas }\end{array}$ \\
\hline $\begin{array}{l}\text { Handa } \\
(2019)\end{array}$ & $\begin{array}{c}\text { Desalinhamento da } \\
\text { fachada e imperfeições } \\
\text { no acabamento }\end{array}$ & Execução & $\begin{array}{l}\text { Falta de alinhamento e prumo entre os painéis } \\
\text { cimentícios }\end{array}$ \\
\hline $\begin{array}{l}\text { Handa } \\
(2019)\end{array}$ & Corrosão dos perfis & $\begin{array}{l}\text { Projeto ou } \\
\text { Execução }\end{array}$ & $\begin{array}{l}\text { Inexistência ou danos em manta impermeabilizante } \\
\text { (asfáltica) entre os painéis e o piso dos pavimentos }\end{array}$ \\
\hline $\begin{array}{l}\text { Handa } \\
(2019)\end{array}$ & $\begin{array}{l}\text { Problemas com ruídos } \\
\text { decorrentes do uso }\end{array}$ & $\begin{array}{l}\text { Projeto ou } \\
\text { Execução }\end{array}$ & $\begin{array}{l}\text { Inexistência de manta acústica entre os painéis e o piso } \\
\text { dos pavimentos }\end{array}$ \\
\hline $\begin{array}{l}\text { Handa } \\
(2019) ; \\
\text { Andrade } \\
(2017)\end{array}$ & $\begin{array}{l}\text { Fissuras e trincas } \\
\text { contornando as placas }\end{array}$ & $\begin{array}{l}\text { Projeto ou } \\
\text { Execução }\end{array}$ & $\begin{array}{l}\text { Falhas na paginação das placas ou irregularidades no } \\
\text { tratamento de juntas de movimentação, por não seguir } \\
\text { recomendações do fabricante }\end{array}$ \\
\hline $\begin{array}{l}\text { Handa } \\
(2019)\end{array}$ & $\begin{array}{l}\text { Estanqueidade e integridade } \\
\text { dos materiais prejudicadas }\end{array}$ & Execução & $\begin{array}{c}\text { Cortes indevidos nos painéis para passagem de } \\
\text { instalações }\end{array}$ \\
\hline
\end{tabular}




\begin{tabular}{|c|c|c|c|}
\hline Autores & Manifestações Patológicas & Origem & Causas \\
\hline $\begin{array}{l}\text { Campos } \\
\text { e Souza } \\
(2010)\end{array}$ & $\begin{array}{l}\text { Manchas de umidade, bolor } \\
\text { destacamento do } \\
\text { revestimento e estofamento } \\
\text { visível e imediato das placas }\end{array}$ & $\begin{array}{l}\text { Projeto ou } \\
\text { Execução }\end{array}$ & $\begin{array}{c}\text { Danos provocados por falhas no sistema hidráulico e } \\
\text { de coleta de água de chuva (calhas, rufos etc.) }\end{array}$ \\
\hline $\begin{array}{l}\text { Campos } \\
\text { e Souza } \\
(2010)\end{array}$ & Danos estéticos e funcionais & Utilização & $\begin{array}{c}\text { Fixação de objetos nas paredes da edificação de } \\
\text { maneira inadequada }\end{array}$ \\
\hline $\begin{array}{l}\text { Campos } \\
\text { e Souza } \\
(2010)\end{array}$ & $\begin{array}{l}\text { Trincas e fissuras rente ao } \\
\text { teto }\end{array}$ & $\begin{array}{l}\text { Projeto ou } \\
\text { Execução }\end{array}$ & $\begin{array}{l}\text { Falta de juntas de dilatação com o objetivo de } \\
\text { promover um espaçamento no encontro entre as } \\
\text { paredes com o teto, permitindo a movimentação } \\
\text { térmica natural. }\end{array}$ \\
\hline $\begin{array}{l}\text { Carvalho } \\
(2015) \\
\text { apud } \\
\text { Hofmann } \\
(2015)\end{array}$ & $\begin{array}{l}\text { Fissuras, trincas inclinadas e } \\
\text { deslocamento das placas } \\
\text { cimentícias }\end{array}$ & Projeto & $\begin{array}{l}\text { Especificação de fundações inadequadas, com } \\
\text { comportamento flexível, proporcionando } \\
\text { deformações além da considerada admissível }\end{array}$ \\
\hline $\begin{array}{l}\text { Hofmann } \\
\quad(2015)\end{array}$ & $\begin{array}{l}\text { Redução no desempenho do } \\
\text { sistema, podendo gerar } \\
\text { movimentações e } \\
\text { deslocamentos indesejados }\end{array}$ & Execução & $\begin{array}{c}\text { Não obediência rigorosa das indicações } \\
\text { fornecidas pelos fabricantes sobre a quantidade } \\
\text { de parafusos necessária para a fixação das placas } \\
\text { e outros elementos do sistema }\end{array}$ \\
\hline
\end{tabular}

Fonte: Autores (2020)

Dentre os danos mencionados, observa-se que afetam, predominantemente, o aspecto estético da edificação. No entanto, algumas medidas terapêuticas precisam ser adotadas.

Lira e Lordsleem Júnior (2018) apontam para a conveniência da substituição dos elementos danificados. Os autores discorrem sobre a identificação de desaprumos verticais da edificação, que pode ser pontual - em uma placa específica - ou generalizada. A depender da situação, observa-se a necessidade de procedimentos distintos de reparo, uma vez que desaprumos pontuais podem ser solucionados com a substituição da placa e desaprumos generalizados deve-se recuperar a verticalidade da estrutura de suporte. Sobre as técnicas de recuperação, a literatura é ainda mais escassa, sendo as principais recomendações relacionadas com a boa prática construtiva, a fim de mitigar problemas futuros. Dentre as principais recomendações gerais, encontra-se a necessidade de seguir rigorosamente as indicações construtivas fornecidas pelos fabricantes, de promover o constante treinamento da mão de obra e de fomentar a boa orientação das particularidades da tecnologia aos usuários, por meio de manuais de usos (bem elaborados) disponibilizados no ato da entrega do imóvel.

\subsection{Vedações verticais interna de bloco de gesso.}

A gipsita (CaSO4.2H2O), material utilizado para a fabricação dos blocos de gesso, já era empregada pelos egípcios na antiguidade, observando seu emprego em 2700 a.C como material de vedação na pirâmide de Quéops (PESTANA et al., 2014). No Brasil, o uso desse material teve destaque nos anos 50, mas com poucos registros (ibid.). Atualmente, o Brasil possui uma reserva de rochas calcárias e dolomíticas estimada em cerca de 350 milhões de toneladas (LEITÃO, 2005). Conforme Barbosa, Ferraz e Santos (2014), o maior produtor de gesso do país é o estado Pernambuco, que concentra $95 \%$ da produção. Notando-se que do gesso natural obtido através da calcinação da gipsita, cerca de $96 \%$ destina-se diretamente ao emprego na construção civil para a confecção de blocos e placas. A vedação vertical interna constituída de bloco de gesso é definida, segundo o SINAT (p. 4, 2017), como alvenaria construída "utilizando blocos de gesso, maciços ou vazados, intertravados e unidos entre si com aplicação de gesso-cola ao longo de todas as arestas". No Brasil, são fabricados blocos com comprimento e altura de $666 \mathrm{~mm}$ x $500 \mathrm{~mm}$, nas espessuras de $70 \mathrm{~mm}, 76 \mathrm{~mm}$ e $100 \mathrm{~mm}$, podendo ser maciços ou vazados, sendo os de $100 \mathrm{~mm}$ produzidos somente na versão maciça (SILVA; PERES, 2016). 


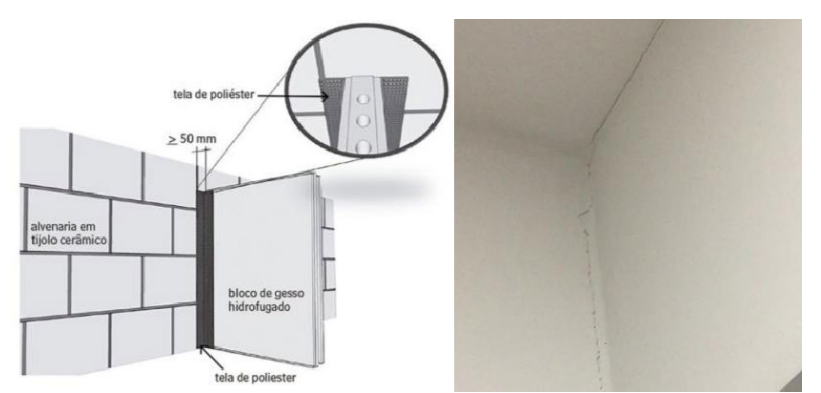

Figura 5 - Modelo e manifestação patológica em vedação de Bloco de gesso Fonte: Silva e Peres (2016)

Conforme o levantamento realizado, um sintoma comumente observado nesse tipo de sistema de alvenaria é a presença de fissuras. Elas ocorrem, geralmente, ao redor das esquadrias e no encontro entre a parede e os elementos estruturais e na interface entre a parede e forro ou entorno das esquadrias. Esses locais são propícios ao surgimento de manifestações patológicas, principalmente, devido à concentração de tensões $(\mathrm{MOCH}, 2011)$.

Essa problemática, não obstante, também é observada nas vedações de bloco de gesso. Lira (2019) ao analisar uma edificação do Recife, cujas paredes internas eram constituídas por blocos de gesso, pôde perceber a presença dos supracitados sintomas. Segundo a autora, o provável mecanismo relacionado à fissura entre a parede de bloco de gesso e a estrutura de concreto ou forro de gesso é o movimento diferencial dos elementos. O Quadro 3 apresenta alguns problemas identificados por alguns pesquisadores.

Quadro 3 - Síntese das principais manifestações patológicas identificadas por pesquisas em vedações internas de bloco de gesso

\begin{tabular}{|c|c|c|c|}
\hline Autor & $\begin{array}{c}\text { Manifestação } \\
\text { Patológica }\end{array}$ & Origem & Causa \\
\hline LIRA, 2019 & $\begin{array}{c}\text { Fissuras ao longo das } \\
\text { juntas }\end{array}$ & Execução & $\begin{array}{c}\text { Irregularidades nas juntas } \\
\text { demovimentação, por não seguir } \\
\text { recomendações do fabricante }\end{array}$ \\
\hline $\begin{array}{c}\text { MOCH, 2011 } \\
\text { LIRA, 2019 }\end{array}$ & $\begin{array}{c}\text { Fissura no entorno das } \\
\text { aberturas }\end{array}$ & Execução & $\begin{array}{c}\text { Ausência de verga e contra-verga } \\
\text { conforme recomendações dos } \\
\text { fabricantes }\end{array}$ \\
\hline $\begin{array}{c}\text { WALKER; } \\
\text { PAÍVA; } \\
\text { DALTON, } \\
\text { 2015 }\end{array}$ & Umidade & Execução & $\begin{array}{c}\text { Utilização de blocos inadequados } \\
\text { na construção }\end{array}$ \\
\hline
\end{tabular}

Fonte: Autores (2020)

Apesar de notar que a maioria das manifestações tem origem na execução, em um estudo realizado por Galiza et al. (2017), conclui-se que muito problemas surgem devido inadequações observadas nas condições iniciais do local de trabalho. Dentre as negligências presentes nessa fase, destacamse a falta de chapisco, contrapiso e limpeza no local onde será construída a vedação, não segmento do projeto de logística para armazenamento dos blocos e ausência de ficha de verificação de serviço, o que tem contribuído para realização do serviço de maneira inadequada.

Além disso, em uma avaliação pós-ocupação feita por Sobrinho (2018) em 15 empreendimentos na região metropolitana de Recife, percebeu-se que a origem das poucas manifestações patológicas encontradas nas edificações decorreu das falhas de projeto e a falta do cumprimento de especificação. Com base no exposto, destaca-se que muitas manifestações patológicas podem ser evitadas se o projeto e a execução da alvenaria de bloco de gesso seguir as recomendações previstas em normas, diretrizes, manuais e determinadas referências bibliográficas. 
Lira (2019) acrescenta a necessidade de aplicação de uma tela de poliéster de largura mínima de $50 \mathrm{~mm}$ em cada lado da vedação para unir a parede e o pilar, conforme apresentado na figura 3. Após o aparecimento das manifestações, é importante definir as terapias que devem ser aplicadas a fim de solucionar o problema. De acordo com Lira (2019), as fissuras podem ser reparadas com a utilização de massa de gesso. Todavia, essa é uma solução para fins estéticos, sendo necessário sanar também a causa da fissura para que ela não volte a ocorrer na vedação de bloco de gesso. Desta forma, recomenda-se a reconstrução da vedação seguindo as recomendações de execução citadas acima.

\subsection{Sistema de vedações verticais internas e externas sem função estrutural de painéis vazados de geopolímero.}

O primeiro estudo que surgiu no mundo sobre geopolímeros foi realizado por Davidovits (1988), que desenvolveu uma investigação experimental que culminou na formulação de compostos inorgânicos de base polimérica, com produtos de propriedades cimentícias, redução de tempo de pega e elevada estabilidade, entre outros. Desde então, muitos trabalhos foram dedicados nos últimos 30 anos ao desenvolvimento de materiais de construção, como geopolímeros, com o objetivo de reduzir os custos ambientais e econômicos de edificações verticais ao longo de toda a sua vida (GALLIPOLI, 2017).

Dentre esses materiais, destaca-se os painéis vazados de geopolímero, que com surgimento recente, estão sendo utilizado no mercado da construção civil brasileiro. De acordo com o Sistema Nacional de Avaliações Técnicas (SINAT, 2020), os painéis vazados de geopolímero são produzidos por processo de extrusão, com a inclusão de adições em sua composição, como pó da borracha de pneu ou de poliestireno expandido (EPS).

Estes painéis se caracterizam por serem intertravados entre si, construídos com aplicação de argamassa cimentícia convencional, em todas as arestas. As Figura 6 e 7 apresentam um modelo de vedação com painéis vazados de geopolímeros com as dimensões máximas de cada peça a fim de evitar possíveis esforços de flexão que danifique o painel durante o seu transporte. Para isso, a largura deve ser compreendida entre 0,80 a $12,0 \mathrm{~cm}$, altura e comprimento máximo de 35,0 e 30,0 $\mathrm{cm}$, respectivamente.

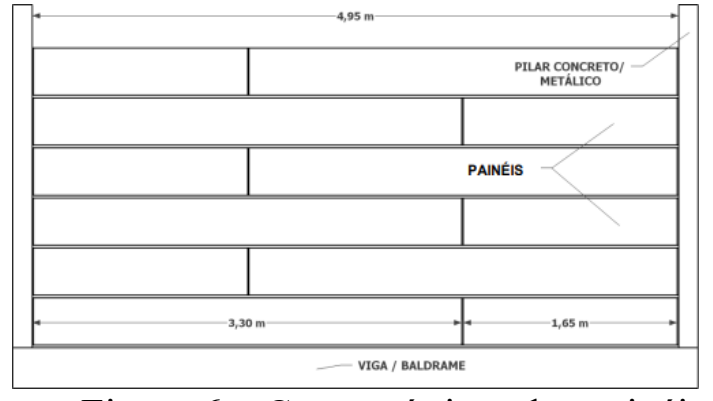

Figura 6-Características dos painéis vazados de geopolímeros

Fonte: SINAT (2020)

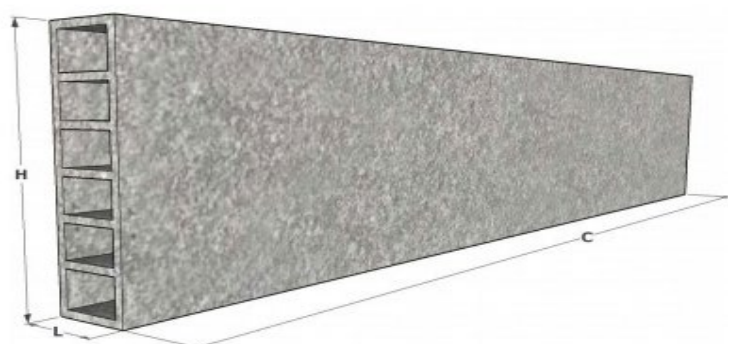

Figura 7 - Exemplo de peça vazada de geopolímero

Fonte: SINAT (2020)

A fim de evitar o aparecimento de possíveis manifestações patológicas o SINAT (2020) cita algumas restrições de uso, como: durante o uso da edificação é de grande importância que seja realizada a com o piso; é proibido o uso de revestimentos compostos com solventes nos painéis geopoliméricos; e deve ser feita uma análise do potencial de surgimento de problemas de umidade nos projetos antes da sua instalação, devido a condensação de umidade interna às unidades.

Além de ser completamente sustentável (PROVIS et al, 2015), Zhang et al (2013), aponta outras múltiplas vantagens do material, como alta resistência a compressão e alta resistência ao fogo. 
Contudo, os geopolímeros também apresentam desvantagens, como alta suscetibilidade ao fenômeno da eflorescência (ZHANG et al, 2013).

Para Cassel (2018), geopolímeros em geral apresentam uma tendência natural à eflorescência, que é causada pelo fato de sua microestrutura ser aberta e porosa, com materiais que possuem uma menor extensão de reação, parcialmente devido à alta concentração de álcalis, como o sódio e em contrapartida ligantes com fraca reatividade (e permutabilidade) do sódio na estrutura de geopolímeros. De acordo com Guterres (2016), o processo de deterioração causado pela eflorescência está mais diretamente ligado à fatores como: migração da água do solo na direção das faces livres das paredes; infiltrações da água da chuva, por condensação do vapor de água contido no interior dos edifícios; água advinda dos materiais de construção e/ou do processo construtivo. No Quadro 4, pode ser visualizado a relação dessa manifestação patológica com a sua causa e origem.

\begin{tabular}{|c|c|c|c|}
\hline \multicolumn{4}{|c|}{ Quadro 4 - Origens e causas da eflorescência em geopolímeros } \\
\hline Autor & $\begin{array}{c}\text { Manifestação } \\
\text { Patológica }\end{array}$ & Origem & Causa \\
\hline Guterres (2016) & Eflorescência & $\begin{array}{c}\text { Projeto ou } \\
\text { execução }\end{array}$ & $\begin{array}{c}\text { Ascenção capilar, infiltração, } \\
\text { água de materiais de } \\
\text { construção. }\end{array}$ \\
\hline
\end{tabular}

Fonte: Autores (2020)

Se as manifestações patológicas em painéis vazados de geopolímeros são geradas através de umidade excessiva proveniente da falha do sistema de impermeabilização ou de materiais de construção, os reparos estão associadas simplesmente as soluções do problema externo (gerador da presença excessiva da água) e a escovação a seco a superfície com escova de cerdas de aço e proceder a limpeza com solução de ácido muriático a lavagem da superfície exterior para eliminar os depósitos de sais que nela se manifestam (NBR 7200, 1998).

\subsection{Painel de vedação sem função estrutural pré-fabricado em concreto.}

Por volta dos anos 50, período pós-guerra, os painéis de concreto foram introduzidos no mercado mundial, destacando sua utilização nos Estados Unidos, Canadá e Europa. Na década de 60 houve um declínio devido as limitações de padronização e estética. Atualmente, no Brasil, São Paulo é o estado que se destaca nesta tecnologia (M. SILVA; V. SILVA; 2017).

$\mathrm{O}$ pré-fabricado em concreto (PFC) para vedação consistem em um sistema reforçado que não possui finalidade estrutural, sendo-os acoplados aos elementos estruturais do empreendimento (CAMPOS, 2019). Podem ser utilizados na parte interna da edificação, como divisórias de ambientes, ou na parte externa, também conhecidos como painéis cortinas, em que as solicitações aos painéis são transferidas aos elementos estruturais (MEDEIROS et al., 2014).

O PFC é comumente utilizado em substituição à alvenaria de vedação com blocos cerâmicos, que consiste em um conjunto de tijolos ou blocos coesos e unidos entre si. Esse conjunto é rígido e possui interposição de argamassa em combinação de juntas que são utilizados em elementos construtivos de vedação como paredes internas e externas. Podem ser fabricados em cerâmica ou concreto (AMBROZEWICZ, 2015). Os PFC são utilizados para vedação devido à redução no cronograma da obra e velocidade de execução nos processos construtivos, em comparação à alvenaria de vedação com blocos cerâmicos. Podendo também promover o aumento de produtividade através da utilização de pré-moldados ou pela produção in loco em que há a facilidade do know-how da mão-de-obra (CRUZ et al., 2018). Além disso, há outras vantagens como a padronização dos painéis, durabilidade compatível com a vida útil do projeto, variedade de dimensões e incorporação de outros materiais na composição do concreto (REIS; RIBEIRO, 2019). Apesar das diferentes vantagens que os PFC possam apresentar para o uso em vedações, existem 
também suas desvantagens como o alto custo, grande peso, falta de normalização e necessidade de precisão em suas dimensões (SILVA, M.; SILVA, V.; 2017).

Além disso, algumas manifestações patológicas podem ser encontradas nos PFC em decorrência de diferentes fatores, mas sendo os mais comuns com origens no projeto e no processo de execução. O Quadro 5 apresenta as manifestações patológicas no PFC.

Quadro 5 - Síntese das principais manifestações patológicas identificadas por pesquisas envolvendo o estudo de PFC

\begin{tabular}{|c|c|c|c|}
\hline Autor & $\begin{array}{c}\text { Manifestação } \\
\text { Patológica }\end{array}$ & Origem & Causa \\
\hline $\begin{array}{c}\text { Silva, M.; Silva, V. } \\
\text { (2017); }\end{array}$ & $\begin{array}{c}\text { Fissura e } \\
\text { problemas com } \\
\text { estanqueidade }\end{array}$ & $\begin{array}{c}\text { Projeto ou } \\
\text { execução }\end{array}$ & $\begin{array}{c}\text { Falhas no armazenamento, transporte, içamento e } \\
\text { fixação das peças acarretam movimentações na peça } \\
\text { e solicitações excessivas }\end{array}$ \\
\hline Acosta (2016) & Fissuras & $\begin{array}{c}\text { Projeto ou } \\
\text { execução }\end{array}$ & $\begin{array}{c}\text { Painéis com pouca espessura e Baixa resistência ao } \\
\text { fogo e baixo desempenho térmico }\end{array}$ \\
\hline $\begin{array}{c}\text { Silva, M.; Silva, V. } \\
(2017)\end{array}$ & Manchas & $\begin{array}{c}\text { Projeto ou } \\
\text { execução }\end{array}$ & $\begin{array}{c}\text { Ação de agentes agressivos que provocam manchas } \\
\text { devido a umidade }\end{array}$ \\
\hline
\end{tabular}

Fonte: Autores (2020)

De acordo com Silva, Campos e Santos Filho (2017) as fissuras podem ser reparadas com a injeção de ligantes epoxídicos não plastificados ou polissulfetos. Lembrando-se que o material deve apresentar resistência à tração maior que a da peça e deve ser relativamente flexível para acompanhar movimentação da fissura. Já com relação às manchas, os autores supracitados recomendam a limpeza do local através de lixamento e escovação, além da utilização de soluções aquosas de bicarbonato de sódio, jatos de ar ou água, como ilustrado da Figura 8.

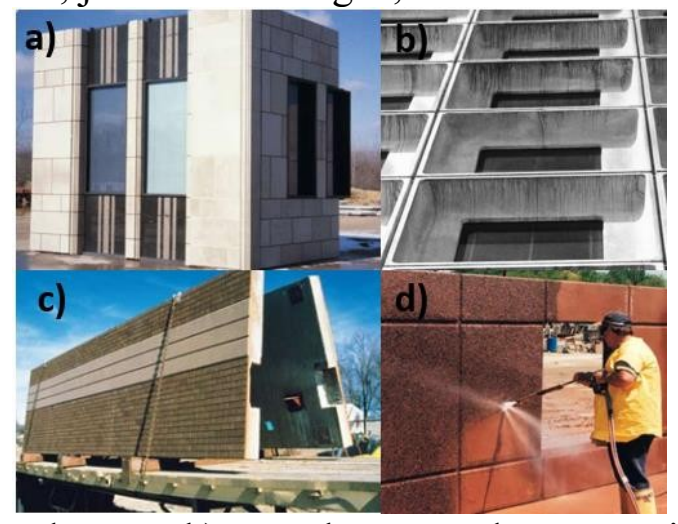

Figura 8-a) Exemplificação de PFC; b) Manchas causadas por umidade; c) Transporte correto de peças; d) Limpeza das peças utilizando jato de água

Fonte: Precast/Prestressed Concrete Institute (2007)

\section{PLANO DE MANUTENÇÃO PREVENTIVA}

O plano de manutenção é um componente que contribui para a conservação das características do empreendimento, como também garante o seu correto funcionamento e condições de utilização. Com o objetivo de reduzir ou impedir o surgimento de eventuais manifestações patológicas nas diversas instalações apresentadas nesta pesquisa, o capítudo em epígrafe constitui brevemente um plano de manutenção preventiva que agrega a confiabilidade dos sistemas e conservação dos seus elementos constituintes, possibilitando a antecipação e redução de falhas indesejadas.

As atividades apresentadas no Quadro 7 do plano de manutenção preventiva que é direcionado para as vedações verticais internas e externas (inclusive muros), podem ser realizadas por profissional devidamente habilitado ou por uma equipe de manutenção terceirizada pelo usuário, sendo em ambos os casos necessário realizar a emissão de ART (Anotação de Responsabilidade Técnica) e elaborar um relatório técnico contendo todas as informações necessárias para futuras inspeções, 
como atividades realizadas e falhas encontradas com registros fotográficos. Para um melhor entendimento dos responsáveis pela execução do plano apresentado a seguir, os sistemas constituintes são todos abordados nos capítulos anteriores, cabendo salientar que deve ser tomada a devida atenção na execução da atividade relacionando ao sistema corretamente.

Quadro 7 - Plano de Manutenção Preventiva

\begin{tabular}{|c|c|c|}
\hline Atividade & Procedimentos & Periodicidade \\
\hline $\begin{array}{l}\text { Verificação de vazamentos } \\
\text { nas instalações }\end{array}$ & $\begin{array}{l}\text { Deve ser resolvido de imediato para evitar a ação } \\
\text { prolongada da água sobre o bloco de gesso. Evitar o uso } \\
\text { de ferramentas contundentes como talhadeiras e } \\
\text { ponteiros, que possam provocar vibração excessiva na } \\
\text { parede e comprometê-la. Consultar um profissional } \\
\text { qualificado para a realização do reparo. }\end{array}$ & Constantemente \\
\hline Limpeza em placas de aço & $\begin{array}{l}\text { Em áreas molhadas pode ser realizada com água, } \\
\text { esponjas, escovas macias, pano úmido e produtos de } \\
\text { limpeza neutros, que não agridam os componentes de } \\
\text { acabamento. Em áreas secas deve ser feita com pano } \\
\text { seco para não danificar o sistema. }\end{array}$ & $\begin{array}{c}\text { Cada } 01 \text { mês ou a critério } \\
\text { do usuário }\end{array}$ \\
\hline Pintura em placas de aço & $\begin{array}{c}\text { Caso haja microfissuras aparentes na peça, consultar um } \\
\text { profissional qualificado para avaliar a necessidade de } \\
\text { substituição total ou parcial da peça }\end{array}$ & Cada 24 meses \\
\hline $\begin{array}{l}\text { Verificação de alterações nas } \\
\text { juntas de movimentação }\end{array}$ & $\begin{array}{c}\text { Caso haja algum problema visível na peça, consultar um } \\
\text { profissional qualificado para avaliar a necessidade de } \\
\text { substituição ou reparo da peça }\end{array}$ & Cada 12 meses \\
\hline $\begin{array}{c}\text { Verificar a segurança e } \\
\text { integridade do sistema como } \\
\text { um todo }\end{array}$ & \multirow{4}{*}{$\begin{array}{l}\text { Documentar com fotos todas as não conformidades } \\
\text { encontradas }\end{array}$} & Cada 24 meses \\
\hline $\begin{array}{l}\text { Verificar os sistemas de } \\
\text { impermeabilização }\end{array}$ & & Cada 24 meses \\
\hline $\begin{array}{c}\text { Verificar a estanqueidade } \\
\text { dos encontros entre o sistema } \\
\text { de vedação e as esquadrias }\end{array}$ & & Cada 24 meses \\
\hline $\begin{array}{l}\text { Verificar manchas de } \\
\text { umidade }\end{array}$ & & Cada 24 meses \\
\hline
\end{tabular}

\section{CONCLUSÃO}

Fonte: Autores (2020)

O objetivo do presente trabalho foi apresentar as manifestações patológicas mais frequentes em vedações verticais inovadoras, expondo suas principais causas e origens e propondo soluções de reparos dos problemas. Com o estudo, pôde-se entender as características e especificidades de cada tecnologia, apontando, falhas frequentes em múltiplas fases da construção que, por sua vez, podem vir a desencadear diversos problemas. Com o exposto, observou-se que grande parte dos problemas patológicos é resultado de deficiência no projeto e no planejamento da construção, onde houve carência de cuidado no seguimento de normas e parâmetros já pré-estabelecidos. Dentre os tipos de manifestações notados nas tecnologias, destacam-se a fissura e problemas com a umidade.

Além de deficiências na fase de projeto e planejamento de execução, uma parte significativa dos problemas patológicos é resultado de falta mão de obra qualificada, sendo um fator primordial na garantia do bom desempenho das edificações. Profissionais bem formados para entender e executar os projetos desenvolvidos é imprescindível.

Espera-se que o apanhado de conhecimento adquirido possa contribuir para a área acadêmica da área da engenharia civil, como também para uma maior conscientização de empresas inseridas na indústria da construção. 


\section{REFERÊNCIAS}

ACOSTA, M. J. M. Desempenho da resistência ao fogo de elementos construtivos de vedação vertical de concreto com formas permanentes de PVC. Tese (doutorado em Engenharia) UNIVERSIDADE FEDERAL DO RIO GRANDE DO SUL. Porto Alegre-RS. 94f., 2019

AMBROZEWICZ, P. H. L. Construção de Edifícios do início ao fim da obra. $1^{\text {a }}$ edição. São Paulo, 2015.

ANDRADE, T. C. de. Inspeção no Pós Ocupação de Empreendimento de Interesse Social em "Light Steel Frame”. 2017. 97 f. Monografia (Especialização) - Curso de Pós-Graduação em Gerenciamento de Obras, Universidade Tecnológica Federal do Paraná, Curitiba, 2017.

ASSOCIAÇÃO BRASILEIRA DE NORMAS TÉCNICAS. NBR 6118: Projeto e execução de obras de concreto. Rio de Janeiro, 1982.

. NBR 15575: Desempenho. Rio de Janeiro, 2013.

BARBOSA, A. A.; FERRAZ, A. V.; SANTOS, G. A. Características químicas, mecânicas e morfológicas do gesso $\beta$ obtido do pólo do Araripe. Ceramica, v. 40, n. 1, p. 501 - 508, 2014.

CÂMARA BRASILEIRA DA CONSTRUÇÃO CIVIL (CBIC). Catálogo de inovação na construção civil. Brasília: CBIC, 2016. 137p.

CAMPOS H. C., SOUZA H. A. Avaliação pós-ocupação de edificações estruturadas em aço, focando edificações em light steel framing. CONSTRUMETAL - CONGRESSO LATINOAMERICANO DA CONSTRUÇÃO METÁLICA, São Paulo. Anais [...]. São Paulo, 2010.

CAMPOS, S. A. Análise comparativa de sistemas de vedações externas para edificações habitacionais com apoio à decisão multicritério. Dissertação (Mestrado em Engenharia Civil) Centro de Tecnologia, Programa de Pós-Graduação em Engenharia Civil: Estruturas e Construção Civil, Universidade Federal do Ceará, Fortaleza, 2019.

CASSEL, L. D. Manifestação patológica em sistemas geopoliméricos produzidos com metacaulim: avaliação da susceptibilidade no desenvolvimento de eflorescências. Monografia (Graduação em Engenharia Civil) - Universidade Federal do Rio Grande do Sul, Porto Alegre, 2018.

CRASTO, R. C. M. Arquitetura e Tecnologia em Sistemas Construtivos Industrializados. 2005. 231p. Dissertação (Mestrado em Engenharia Civil). Universidade Federal de Ouro Preto. Ouro Preto, Minas Gerais, 2005.

CRUZ, H. M.; SANTOS, D. G.; MENDES, L. A. Causas da variabilidade do tempo de execução dos processos em diferentes sistemas construtivos. Ambiente Construído, v. 18, n. 1, p. 49-65, 2018.

CONFERÊNCIA NACIONAL DE PATOLOGIA E RECUPERAÇÃO DE ESTRUTURA, 2017, Recife. Anais [...], CONPAR, 2017, 2017.

DAVIDOVITS, J. Geopolymer chemistry and properties, proceedings of the geopolymer, v.1, p. 25-48, 1988.

GALIZA, L.; JUNIOR, M. J. S.; ALBUQUERQUE; M. V. F.; BEZERRA, M. Manifestações patológicas em vedações de gesso e a importância de uma gestão eficaz no processo. 
GUTERRES, P. R. C. Argamassas de reabilitação: Estudo da sua utilização e do seu comportamento para o tratamento e recuperação de construções afetadas por eflorescências. 2016. Tese (Doutorado em Engenharia Civil) - Universidade da Beira Interior, Corvilhã, Portugal. 2016.

HANDA, D. K. C.. Identificação das Principais Manifestações Patológicas em Fachadas em Chapas Delgadas Estruturadas Em Light Steel Framing - Estudos de Caso. 2019. $204 \mathrm{f}$.

Dissertação (Mestrado) - Curso de Engenharia Civil, Universidade Estadual de Campinas, Campinas, 2019.

HENRIQUES, F. M. A. Noção de Qualidade em Edifícios. Comunicação ao Congresso Nacional da Construção. Lisboa, 2001.

HOFMANN, G. A. A. Tratamentos de Juntas Invisíveis em Placas Cimentícias no Fechamento de Sistemas Light Steel Framing. 2015. 105 f. Dissertação (Mestrado em Engenharia Civil) - Pro grama de Pós- Graduação do Departamento de Engenharia Civil, Universidade Federal de Ouro Preto, Ouro Preto, 2015.

Isoeste. Disponível em: https://kingspan-isoeste.com.br/Acesso em: 10 Set. 2020.

IBDA - Instituto Brasileiro de Desenvolvimento da Arquitetura. Disponível em: http://www.forumdaconstrucao.com.br/ibda.php. Acessado em: 25 de out. de 2020.

LEITÃO, M. A. S. Gesso: conhecimento e uso na engenharia. In: Congresso Brasileiro de Ensino de Engenharia. 2005, Recife. Anais [...], 2005.

LIMA, B. S. Principais manifestações patológicas em edificações residenciais multifamiliares. Trabalho de conclusão de curso (Graduação em Engenharia Civil) - Universidade Federal de Santa Maria, Santa Maria, 2015.

LIRA, V. Q. Manifestações patológicas em vedações verticais inovadoras: estudo de caso. Dissertação (Mestrado em Construção Civil) - Universidade de Pernambuco, Recife, 2019.

LIRA, V.; LORDSLEEM JUNIOR, A. C. Manifestações Patológicas em Inovações Técnológicas das Vedações Verticais de Edificações Habitacionais. In: Congresso De Patología y Rehabilitacíon de Edificios, 6., 2018, Rio de Janeiro. Anais [...]. Rio de Janeiro: POLI/UFRJ, 018. p. 1-10.

PIETRANTONIO, V. B. Tecnologia de Vedação e Revestimentos por fachadas. Instituto Aço Brasil. Rio de Janeiro, 2014.

$\mathrm{MOCH}, \mathrm{T}$. Interface esquadria/alvenaria e seu entorno: análise das manifestações patológicas típicas e proposta de soluções. Dissertação (Mestrado em Engenharia Civil) - Universidade Federal do Rio Grande do Sul, Porto Alegra, 2011.

ORGANISATION FOR ECONOMIC CO-OPERATION AND DEVELOPMENT (OECD). Manual de Oslo: diretrizes para a coleta e interpretação de dados sobre inovação tecnológica. Publicado pela FINEP (Financiadora de Estudos e Projetos), 3 $3^{\mathrm{a}}$ ed., 2005.

PESTANA, E. H. A.; MASCARENHA, K. M.; PINHEIRO, L. H. S.; QUEIROZ, M. G. S. A alvenaria estrutural e seu desenvolvimento histórico: Materiais e sistemas estruturais. 2014. Disponível em: https://pt.slideshare.net/felipelimadacosta/a-alvenaria-estrutural-e-seudesenvolvimento-histrico. Acesso em: 14 de out. 2020.

PRÁVIA, Z. M. C.; BETINELLI, E. A. Conceito e estudo de casos de falhas em estruturas metálicas. Construção Metálica, [São Paulo], p 56-61. 4º trimestre de 1998. 
PROVIS, J. L.; ANGEL, P.; CAIJUN S. Advances in understanding alkali-activated materials. Cement and Concrete Research 78 (2015): 110-125.

REIS, J. V. A.; RIBEIRO, N. C. Comparação decusto entreparede de alvenaria convencional e parede de concreto moldada in loco. Trabalho de conclusão de curso (Graduação em Engenharia Civil) - Centro Universitário Cesmac, 2019, Maceió.

SANTIAGO, A. K. O Uso do Sistema Light Steel Framing Associado a Outros Sistemas Construtivos como Fechamento Vertical Externo Não Estrutural. Dissertação (Mestrado em Engenharia Civil) - Escola de Minas, Universidade Federal de Ouro Preto, Ouro Preto, Brasil, 2008, 168 p.

SILVA, A. C. G.; CAMPOS, G. R.; SANTOS FILHO, M. L. Análise de Manifestações Patológicas em Obras de Arte Especiais - Estudo de Caso e Propostas de Recuperação. Revista Técnico Científica do CREA-PR, Curitiba, p. 1-15, 2017.

SILVA, M. G.; SILVA, V. G. Painéis de Vedação. Rio de Janeiro: Centro de Informações do Aço Brasil CBCA. 59 p. Série Manual de Construção em Aço - Reimpressão, 2017.

SISTEMA NACIONAL DE AVALIÇÃO TÉCNICA (SINAT). Diretriz para avaliação técnica de produtos: Sistema de vedações verticais internas e externas sem função estrutural de painéis vazados de geopolímero. Documento técnico nº 015. Brasília, 2020.

. (SINAT). Diretrizes para Avaliação Técnica de Produtos No 010 - Sistemas construtivos formados por painéis pré-fabricados de chapas delgadas vinculadas por núcleo de isolante térmico rígido. Brasília, 2015.

. (SINAT). Diretrizes para avaliação técnica de produtos No 008 - Alvenaria de blocos de gesso para vedações verticais internas sem função estrutural.Brasília, 2017.

SOBRINHO, C. W. A. P. Utilização de divisórias internas de edifícios em alvenaria de blocos de gesso - foco na sustentabilidade. In: Construções: reabilitar e construir de forma sustentável, 1019, Porto. Anais [...] Porto, 2018.

SOBRINHO, C. W. A.; BEZERRA, N. M.; SILVA, C. B.; COSTA, T. C. T. Vedações verticais em alvenaria de blocos de gesso para estruturas aporticadas de concreto armado- projeto, execução e desempenho. In: 52 Congresso brasileiro do concreto, 2010, Curitiba. Anais [...] 52 COBRACON, 2010.

TREVO. Procedimento de execução de alvenaria de bloco de gesso. Documento técnico. Disponível em: http:/www.trevogesso.com.br/biblioteca/publicacoes-tecnicas/Procedimento- para-execucao-dealvenaria-em-blocos-de-gesso.pdf. Acessado em: 13 de ago. de 2020.

TUNNELTECH. Concreto geopolimérico para revestimentos duráveis. Disponível em: https:/www.tunneltalk.com/TunnelTECH-Jan2014-Sustainable-Earth-Friendly-Concrete-for- highdurability-tunnels.php. Acessado em: 16 de ago. de 2020.

WALKER, R.; PAÍVA, S.; DALTON, M. Measurement of moisture content in solid brick wall using timber dowel. Materials and structures, v. 49, n.7, 2015. 